\title{
The use of disc stack centrifuge in the virgin olive oil industry
}

\author{
Giacomo Costagli \\ Alfa Laval SpA - Edible Oil Systems, Calenzano (FI), Italy
}

\begin{abstract}
The disc stack centrifuge (DSC) in the virgin olive oil (VOO) industry is widely used for oil purification at a final stage of extraction process. The obtained oil should be commercialized directly as turbid or sent to settling and/or filtration. Despite technology is strongly consolidated, few literature is available on the effect of DSC on efficiency and quality of VOO, specially compared with alternative methods. Alternative technologies to DSC like settling or direct filtration are suitable only for very small production scale. Application of advanced technology already available for DSC like hermetic design is applicable also to VOO but more research is necessary to establish effect on quality and cost/benefit ratio. Improvement of installation module and a more appropriate use of DSC on VOO industry are recommended to reduce water consumption and consequent loss of VOO quality.
\end{abstract}

\section{Introduction}

Dr Gustaf de Laval was granted the patent of The Centrifuge for the separation of cream from milk in June 1878. The introduction of centrifuge generates a revolution in a wide range of industrial application and currently the technology is applied throughout many manufacturing industries with different centrifuge designs adapted to particular uses (Beveridge, 2000). Disc stack sedimentation centrifuge (DSC) with radial solids-ejecting are the commonest, and today the most important applications are pro-

Correspondence: Giacomo Costagli, Alfa Laval SpA - Edible Oil Systems, via delle Calandre 53, 50041 Calenzano (FI), Italy.

Tel.: +39.03927041390. E-mail: giacomo.costagli@alfalaval.com

Key words: Olive oil; centrifuge; Alfa Laval; separator; purification.

Acknowledgements: the author thanks Leonard Borgström of Alfa Laval Tumba AB - Sweden, for technical input and information.

Conflict of interests: the author is employee of Alfa Laval SpA (Calenzano, Florence, Italy).

Received for publication: 4 September 2017.

Accepted for publication: 28 October 2017.

(C) Copyright G. Costagli, 2018

Licensee PAGEPress, Italy

Journal of Agricultural Engineering 2018; XLIX:784

doi:10.4081/jae.2018.784

This article is distributed under the terms of the Creative Commons Attribution Noncommercial License (by-nc 4.0) which permits any noncommercial use, distribution, and reproduction in any medium, provided the original author(s) and source are credited. duction of milk, wine, other beverage and purification of vegetable oil, olive oil, fuel and lube oil on ships (Axelsson and Madsen, 2012). The use of centrifugal technology in the virgin olive oil (VOO) industry was introduced for the first time by Alfa Laval in 1927 (Alfa Laval, 1928). The DSC was introduced to purify oil must come from hydraulic press in alternative to the traditional static sedimentation which is a slow process where the oil is in contact with vegetable water and residual solids with consequent contamination. By the use of DSC, the purification becomes a continuous and fast operation with a consequently significant improving of quality of final oil (Frezzotti, 1928). After thirty years from the first introduction, the DSC was extended to most of press traditional mills and was considered and integrated as key technology also in all alternative processing methods proposed at that time as Sinolea, SIMA-Baglioni, Elettrolia, Veraci-Primolia, Dieffenbach and Veraci-Olier (Carole et al., 1964). However, mentioned extraction system not received success on the market due to different problem like oil yield or cost. Once again, the alternative to the press traditional mills was definitively developed by Alfa Laval with the introduction of the new process extraction line named Centriolive. New process extraction line includes the steps of washing, crushing, malaxing and two successive centrifugation steps: the decanter extraction for centrifugation of olive paste in three phases and the DSC used both for final oil purification and for oil recover from black water (Valleggi, 1966; Vitagliano and Radogna, 1967).

During the second half of 1900, and until today, the VOO mill extraction method based on centrifugation by decanter and DSC was going to be consolidated replacing globally the traditional press technology and described into main reference olive oil industry handbooks (Kiritsakis, 1992; Hermoso Fernandez et al., 1995; Civantos, 1999; Di Giovacchino, 2010). Today DSC for oil purification still has a crucial importance in the VOO industry and, as for the other equipment of the extraction plant is contribute to influence the characteristics of the final obtained oil (Costagli, 2006; Servili et al., 2012). Moreover, DSC has been applied for similar process extraction method like cold pressed avocado oil (Costagli and Betti, 2015). Despite that, applied research on the use of DSC for VOO is very limited. The purpose of that review is to look at the level of applied scientific knowledge remarking the importance of the use in the industry with an eye to future innovation challenges.

\section{Basic design and process function}

Centrifuges are classified in sedimentation and filter centrifuges as per exhaustive description of Sokolov (1971). Among sedimentation centrifuges, the disk stack, which discharges intermittently and radially, is the one used in the VOO industry. Process function is based on the fast rotating bowl (speed is about $6000 \mathrm{rpm}$ ) in which the separation, based in the different density between phases, takes place. Figure 1 shows, in a schematic section of rotating bowl, the basic principle function of a DSC used for VOO purification. The incoming oily must (feed) enters in the 
centrifuge via the inlet where it is spun up to the speed of the centrifuge. The feed is thereafter led radially outward in the distributor and it is distributed to the disk stack. The disk stack consists of closely spaced conical discs. To have an efficient centrifuge, a large surface area is needed and about hundred discs are used. The light liquid phase (oil) is continuously separated from the sediment as it goes towards the centre of the bowl. The heavy liquid phase (water) is also continuously separated from the sediment and it goes towards the periphery of the bowl, outside the top disc. When the separated liquids leave the disk stack, it raises upwards and flow out of the bowl through open overflow out ports. Open outlet centrifuges are the most common in the VOO industry. The alternative is the centrifuge equipped with a centripetal pump known as paring disk (not showed). The paring disk converts the kinetic energy of the rotating liquid, and discharges it under pressure. Separated sediment, which is heavier than liquid phases, is forced towards the periphery of the bowl and collected in the sediment space outside the disc stack. Discharge of sediments takes place through several ports in the bowl wall. Discharge occurs today, in an intermittent adjustable way thanks to the sliding bowl bottom (self-cleaning), which has been introduced as important innovation also in the VOO industry, replacing DSC with closed bowl and manual discharge (Baccioni and Peri, 2014). The sliding bowl bottom is forced upwards against a seal ring by a specific liquid force acting on its underside. Discharge should be total, with total emptying of the bowl and processing suspended, or partial, with partial emptying of the sludge space in the bowl without emptying the rest of the bowl and without suspension of processing. Most common in VOO industry is self-cleaning total discharge with intermittency variable in function of dimension of the sediment chamber, flow capacity and characteristics of the inner fluid. Closed bowl and manual discharge DSC are today not used anymore in the VOO industry.

Complete description of theoretical size of a disk stack centrifuge, dimensional parameters and fluid and particles dynamics is reported in the literature (Sullivan and Erikson, 1961; Gupta, 1981; Axelsson and Madsen, 2012).

\section{Purifier}

When operating the centrifuge as a purifier, the objective is to remove residual water (heavy liquid phase) and sediments (solids) from the oil (light liquid phase). The feed oily must flows up and is divided among the discs, where the liquid phases are separated from each other into heavy liquid phase and light liquid phase by action of centrifugal force. The borderline between heavy and light liquid phase is named interface (Figure 1). The position of the interface in the bowl depends on gravity disc diameter $\left(\mathrm{D}_{2}\right)$, density and temperature of the oil and flow rate. Maximum purification of oil is obtained with an interface diameter $\left(\mathrm{D}_{3}\right)$ as largest as possible but smallest than top disc diameter to avoid loss of light liquid phase into heavy liquid phase. Purifier setting of centrifuge is used to purify the oily must come from decanter extraction into VOO extraction process.

\section{Concentrator}

When operating the centrifuge as a concentrator, the objective is to remove residual oil (light liquid phase) from the water (heavy liquid phase). The separation concept and principle is the same described in the previous Purifier paragraph with the difference that maximum recovery efficiency of residual light liquid phase is obtained with an interface diameter $\left(\mathrm{D}_{3}\right)$ as smallest as possible but largest than inner outlet diameter $\left(\mathrm{D}_{1}\right)$ to avoid contamination of heavy liquid phase into light liquid phase (Figure 1). Concentrator setting of centrifuge is used to recover the residual oil from black water come from three phases decanter extraction into VOO extraction process.

\section{Purification of oily must}

The separation of oil from solid and liquid phases is done using a decanter centrifuge. This device exploits the centripetal acceleration to separate continuously a mixture of particulate solids and liquids with phases having different densities (Madsen, 1989). Either two or three phases (or outlets) decanter are today used in the VOO industry. The oil comes out from decanter is sent to a mechanical vibrating or rotating sieve with holes' variable between 1 and $1.5 \mathrm{~mm}$. The oil obtained after mechanical sieving is named oily must and still contains a significant quantity of water and solids impurities. The quantity of water and solids impurities in the oily must is indicated in the literature as average percentage between 1 and 3 (Di Giovacchino et al., 2002; Uceda et al., 2006). More recently, Gila et al. (2017) confirms values in a similar range but, measuring oily must composition during three consecutive extraction seasons, detect a very high variability with a maximum content of water and solids impurities up to $14.9 \%$ during one of the three years of experiments. Large variation in water and solids impurities in the oily must is a very well known phenomenon from oil mill's operators and it is only partially manageable by process parameter adjusting or improving design of decanter. Residual oil in the husk as well as clarification of oily must is mostly related to olive paste rheological characteristics and consequent quantity of
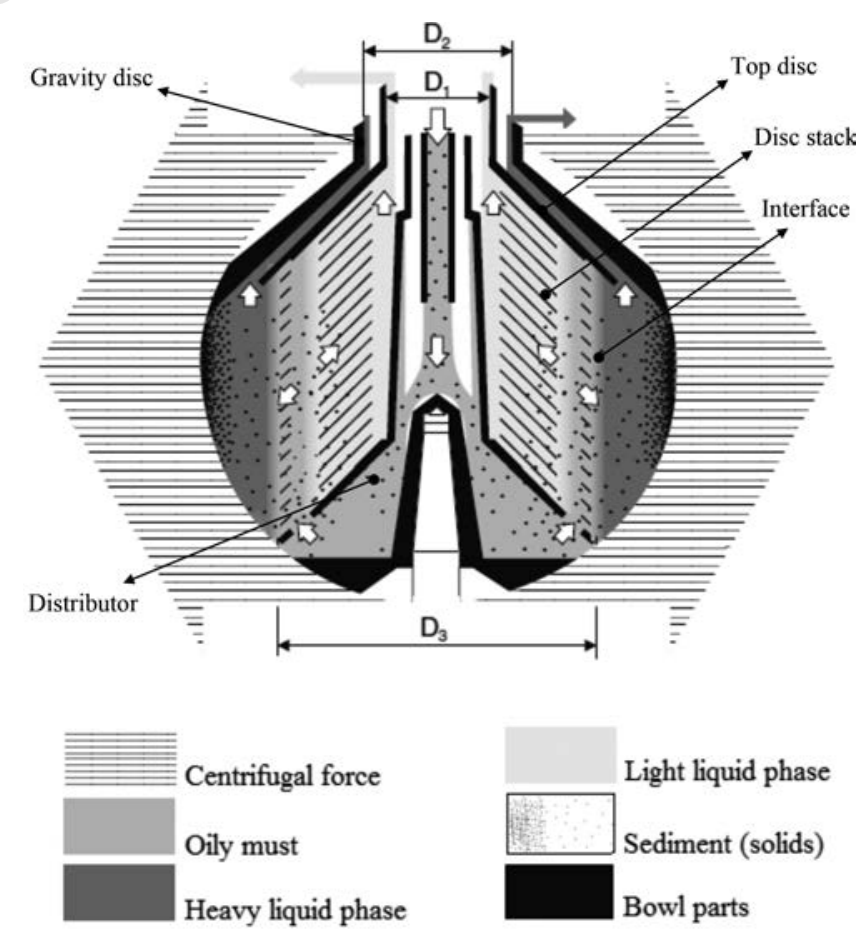

Figure 1. Cross-section of bowl of a disc stack centrifuge with schematic representation of purification function with open discharge. $\left(D_{1}\right)$ Diameter of inner outlet; $\left(D_{2}\right)$ Hole diameter of gravity disc; $\left(D_{3}\right)$ Diameter of interface (courtesy of Alfa Laval). 
oil/water emulsions. Rheological characteristics are strictly related to agro-climate, olive variety or ripeness (Martinez et al., 1957, 1959). Olive paste characterized by emulsion formation, noneffective malaxing and low efficiency in solid-liquid separation has been categorized as difficult paste with consequent high oil losses in by-products as well as low clarification efficiency of oily must (Martinez et al., 1975; Muñoz et al., 1979; Di Giovacchino, 1988). As the recommendation for conservation of VOO is to have residual water content below $0.2 \%$ (International Olive Oil Council, 2015), the oily must is sent to the disk stack centrifuge for purification as last step of the extraction process (Figure 2). Oily must is feed to disk stack centrifuge by adjustable mono pump or by gravity together with an addition of around 5-10\% of fresh water at the same temperature of the feed product. Separation efficiency of centrifuge depends to many variables as composition of oily must, feed rate, gravity disc and related interface position, interval of discharge, quantity and temperature of dilution water. DSC can remove from oily must, solids impurities below $0.1 \%$ and residual water below $0.2 \%$ in optimal operational conditions (Masella et al., 2009; Guerrini et al., 2016). The advantage that make the purifier DSC almost universally used in the VOO industry is the capability to release with a continuous operation, an efficient and constant level of clarification in presence of significant variation in composition of inlet oily must. In fact, Gila et al. (2017) measure a results of water impurities after centrifugation in a short range between $0.51 \%$ and $0.74 \%$ despite large range of variation of water impurities in the inlet oily must.

DSC for oil purification is confirmed today as an essential component of a modern oil mill able to perform in continuous, in a wide available range of sizes and with a very fast contact with the product. Despite that, there are many crucial aspects of regulation and adjustment to be considered in relationship with process costs (water and energy requirement) and quality effect on final VOO. In the follow paragraph, we review separately the principle crucial aspects on light of the limited literature available.

\section{Water dilution}

When the centrifuge operates as purifier, the water used during process is important for different reasons. Every time we start the purification, before to feed oil into DSC, it is necessary to introduce water to create a water seal avoiding the oil flow out through the water outlet. A second use of process water is the flushing of the bowl moving the interface and discharging the bowl of the internal oil before total discharge. On top of all of that, during oily must purification with DSC, manufacturers recommend a dilution up to $10 \%$ of water in volume. Addition of water together with oily must has two main important purposes. Dilution water helps to flush out some of the solids that otherwise would accumulate in the bowl making discharges more frequent and time to clean of bowl shorter with consequent risk to obtain a worst oil purification quality. The second important reason to use water dilution is the necessity to have a shielding of air friction heat generated by spinning bowl. The water flow inside of bowl absorb a significant portion of heat vent, helping keep cool the oil, avoiding temperature increase that should damage the quality. Based on that, temperature of water process is also important. The temperature of dilution water must be at the same temperature of the oily must fed. If temperature of water is lower than oily must, the risk is the production of emulsions with consequent risk of oil loss in the water. If temperature of water is higher than oily must the risk is to increase the temperature of oil with consequent risk of damage for oil quality. In the literature are reported temperature increase of the oil by DSC of 3$4^{\circ} \mathrm{C}$ (Guerrini et al., 2016) as well as $1^{\circ} \mathrm{C}$ (Altieri et al., 2014) also if both research does not indicate necessary information as oil flow rate and inlet temperature of water dilution necessary to discuss the results.

Evaluating the effect on quality of DSC, the main attention is reserved to the differences in total phenols content of the oil before and after treatment. Because during oil purification, water and solids impurities are removed, together are removed all the phenols accompanied in the oily must (Garcia et al., 2001). Because natural phenolic antioxidants are more soluble in the water than in the oil phase and their partition coefficient $(\mathrm{Kp})$ is increased by increase of temperature (Rodis et al., 2002) the quantity and temperature of water dilution during purification with centrifuge, should affect also a partial removing of phenols from oil composition of oily must. Di Giovacchino et al. (1994) reports a reduction of phenols content and induction time when oil is purified with DSC with water dilution of 40 and $80 \%$ in volume compared with no dilution. Similar result is reported in Spain with water dilution of $100 \%$ (Hermoso et al., 1995) or variable dilution from 50 to $100 \%$ with temperature from 30 to $50^{\circ} \mathrm{C}$ (Jimenez Marquez et al., 1995). We must remark that so high water dilution quantity and so high temperature are not in line with best practices recommendation from manufacturer of DSC. When water dilution during oily must purification is reduced to $25 \%$, no significant reduction on total phenols between oily must and purified oil (Masella et al., 2009) as well as research in contrast (Guerrini et al., 2016). The negative impact of DSC on total phenols content on the obtained oil is disappeared when water dilution is used lower than $10 \%$ (Alcalá et al., 2016; Gila et al., 2017). Unfortunately, all cited researches does not take in consideration a full balance of phenols content between oil and water phase and, at the same time, most of them does not consider important parameter as operational temperature, ratio between flow rate and bowl dimension, flushing and discharge interval. By the way, correct adjustment of water dilution flow and temperature are important to ensure the preservation of antioxidant phenols and installation design of oil mill must avoid common mistakes as oversized water dilution valves as well as large variation in line water pressure and temperature.

\section{Dissolved oxygen}

After extraction and during storage the quality of lipids, including $\mathrm{VOO}$, is subjected to progressive deterioration with a development of rancidity caused by oxidation reaction (Harwood

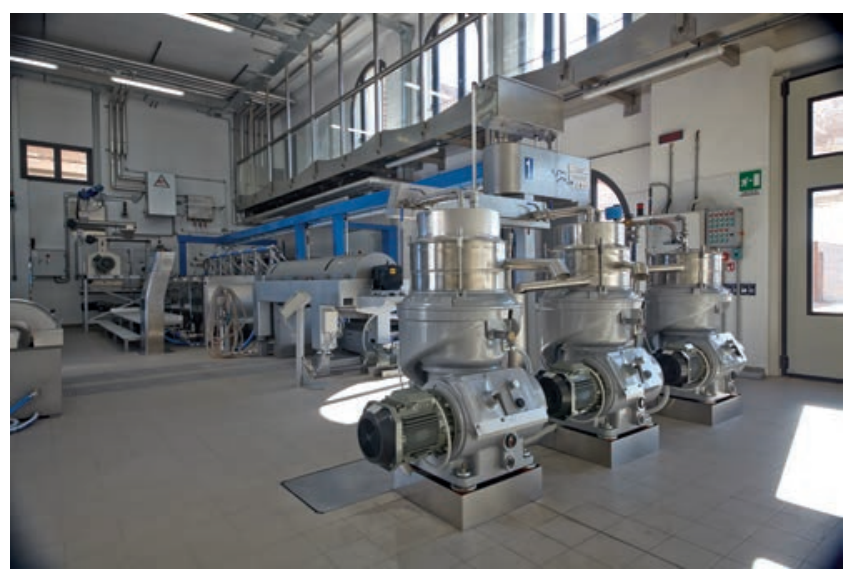

Figure 2. Oil mill equipped with disc stack centrifuge model Alfa Laval UVPX 507 (in foreground) (courtesy of Alfa Laval). 
and Aparicio, 2000). VOO extraction with decanter and then purification with DSC are done, commonly, with open bowl centrifuge. Both steps of centrifugation are continuous and the time contact with air is limited to few seconds of treatment. Moreover, in an open DSC, air is in contact with product from inlet to outlet but most of the dissolved air is naturally stripped out few seconds after outlet. Dissolved oxygen measured in literature show very high variation between 1 and 9 ppm (Ottaviani et al., 2001; Parenti et al., 2007; Sacchi et al., 2008; Masella et al., 2009, 2010, 2012; Guerrini et al., 2016). Large variation is probably due to the different methods and sampling that, in addition, are not correctly defined or missed for the parameter in a DSC. Flow rate in relation with bowl size, composition of oily must before purification, dilution rate and water temperature, sampling time after discharge, sampling time after outlet, are example of parameters could affect the value of dissolved oxygen. Anyway, measured dissolved oxygen amount between 5 and 9 ppm from DSC is considered responsible of an increase of peroxide value and K232 (Masella et al., 2009; Parenti et al., 2012) or in addition to that, also of an oxidation of phenols with consequent reduction of ratio between oxidised and no oxidised forms of secoiridoides (Guerrini et al., 2016). When dissolved oxygen is reduced of $70 \%$ by inert gas blanketing between inlet and outlet during oil purification by DSC, an improvement on peroxide and K232 value is obtained without an effect on phenol content (Masella et al., 2012). As described on paragraph 2, DSC with closed outlet (paring disc) are already available for VOO and are deeply developed and investigated in other application like beer or wine (Costagli et al., 2016). The eventual application of hermetic DSC design on VOO must be well investigated in relation also to the ratio between investment cost and related benefit. All cited studies investigate the effect of dissolved oxygen produced by DSC, on VOO quality comparing oil quality before and after centrifugation. Because oil purification after decanter extraction is necessary, further researches on the effect of dissolved oxygen on VOO quality, are recommended comparing the effect of DSC with alternative technologies.

\section{Alternative technologies}

After 90 years from the introduction of first DSC for oil purification replacing natural sedimentation, a limited quantity of research and development is done to propose alternative technologies. Only during last 20 years some tentative of oil purification was done with alternative technology with purpose to replace DSC. We will review the most significant one objected of research.

\section{Settling tanks}

A prototype plant for oil purification with two settling tanks in series equipped with pumps and VFD was tested in Italy in a lab scale (Genovese et al., 2013) and small industrial scale (Altieri et al., 2014) and compared in parallel with DSC. Similar purification principle based on sedimentation concept but in a continuous flow (hidrocyclone) was investigated by Altieri et al. (2015). Cited researches show an improvement on VOO quality in terms of lower peroxide, K 232 and higher phenols content when VOO is purified with settling tank instead that with DSC underline also reduction on energy consumption. Unfortunately, method of research does not take in consideration important parameter of centrifuge as flow rate and dilution water.

Settling tanks in large industrial scale has been introduced in Spain during last 10 years with objective to replaces DSC claiming same level of purification, continuous operation and reduction of water and energy consumption. System consists of stainless steel conical bottom thanks with the possibility to be used under static or dynamic conditions. To preserve oil quality, systems include an automatic system to purged periodically from the bottom of tanks. An investigation on industrial scale for three entire olive oil seasons in Spain has been carried out by Gila et al. (2017) comparing the bottom settling tank purification with DSC operating with proper water dilution rate. All oil quality parameters were not affected negatively by both experimented purification method except the sensorial analysis with higher score for the oil purified by DSC with respect to the oil purified by settling who appear with defect. Also, purification efficiency was higher the obtained by DSC. Phenolic compounds were affected by both purification systems with a reduction between 13 and $42 \%$ especially for hydroxytyrosol, tyrosol and secoiridoides by settling. While, centrifugation method allowed the conservation of phenols with a consequent improvement of shelf life during storage. Moreover, from operative point of view, settling method allowed higher oil loss together with bottoms and requires more time and personal attention on conduction with respect to DSC (Gila et al., 2017).

\section{Purification and simultaneous filtration by filter}

VOO purified by DSC should contain moisture lower than $0.2 \%$ in accordance to the suggestion for optimal conservation (International Olive Oil Council, 2015) and it should be bottled and commercialized directly as freshly produced. Freshly produced oil is naturally turbid containing micro-droplets of vegetation water and solid particles from olive fruits (Gordillo et al., 2011). Because there are markets who prefer more brilliant oils for better customer acceptance and with the intention to maintain oil quality and increase shelf-life, it is a consolidate practice to filter it. Filtration should be done just after purification by DSC or after a certain storage time with a consequent partial settling. Filtration reduces water content protecting oil by chemical degradation and different systems has been applied for VOO: conventional filtration systems (filter tanks and filter presses), cross-flow filtration (tangential-flow filtration), inert-gas-flow filtration systems, and filter bags (Lozano-Sánchez et al., 2010). Recently, for small or medium scale VOO production, purification and filtration is proposed as a unique treatment of oily must after decanter, without DSC. Fortini et al. (2015) investigate the quality of VOO obtained by simultaneous purification and filtration of oily must from decanter in a unique step with a traditional filter press and cardboard filter pates. Nutritional and sensory quality of purified and filtered oil is significant improved with respect to oily must directly from decanter and method is considered better with respect to the use of DSC. Unfortunately, the research does not compare in parallel the use of filter press with the use of DSC. Moreover, same authors conclude that simultaneous purification and filtration in a unique step become costly in terms of filter plates, oil losses and manpower, underlining, one time more, than filtration and centrifugation are complementary and not alternative operations (Peri, 2014). Similar conclusion is always reached in some food applications where combination of DSC with filtration is deeply investigated. Previous clarification with DSC before filtration, improves quality of final product as well as investment cost and operational cost for filtration in beer or wine (Cimini et al., 2014; Costagli et al., 2016). A recent study investigates the use of DSC on post-production, for further oil purification as unique treatment and in combination with papers filter. Purification done with DSC only was able to produce a general stabilization of veiling, reducing the formation of deposits at the bottom of the oil bottles and keeping a good level of cloudiness without negative impact on quality (Veneziani et al., 2018). The production of stable veiled oil is a fur- 
ther opportunity required by the market and the use of DSC technology for it could represent a new application.

\section{Oil recovery from vegetation water}

A second DSC should be used to recover residual oil from the vegetation water flowing from the three phases decanter. Vegetation water is fed by adjustable mono pump or by gravity to the disk stack centrifuge settled as concentrator without further water dilution and the recovered oil is collected together with oil comes out from purifier centrifuge. The application was largely used in the three phases mills until beginning of 2000 years but literature is not available. Despite the quantity of oil recovered is very limited, the application was considered as a safety way to recover eventual losses from decanter separation due to eventual wrong adjustment, especially when the oil mill elaborates many different qualities of olives batches in short sequence. The latest improvement of the three phases decanter technology reduces to almost $0 \%$ the residual oil in the water and the adjustability of process parameter. Hence, the use of the centrifuge to recover a very limited quantity of VOO from vegetation water is recently abandoned by customer and, in any case, should be evaluated according to economic constraints (Costagli and Betti, 2015).

\section{Conclusions}

After 90 years from the introduction, by Alfa Laval, of DSC for VOO purification, technology is still the unique one able to ensure quality and efficiency on industrial scale production. Alternative technologies like settling tanks and filter are probably applicable only to very small production scale and their efficiency is detectable on punctual experiment but is strongly limited on large industrial scale with a usual variation of oily must composition from decanter. The use of DSC on post-production to obtain stable veiled oils could represent a further opportunity in the future (Veneziani et al., 2018). DSC is object of a continuous development and improvement, inclusive hermetic design, on many different applications. Further and better investigation is necessary, on VOO application, to establish the limits of actual disc stack technology like dissolved oxygen. The extension of use of hermetic design to VOO industry, requires proper investigation and cost/benefit analysis. At the same time, the efficiency of DSC technology actually used, should be improved by an improvement of correct use like a better attention to the use of limited and proper quantity of water dilution.

\section{References}

Alcalá S., Ocaña, M.T., Cárdenas J.R., Miquel M.Á., Vilar J., Espínola F., Moya M. 2016. Alkyl esters content and other quality parameters in oil mill: A response surface methodology study. Eur. J. Lipid Sci. Technol. 119:1600026.

Alfa Laval. 1928. De Laval. Separatori Centrifughi per olio d'oliva. Arti Grafiche Enrico Gualdoni, Milano, Italy, pp. 26.

Altieri G., Di Renzo G.C., Genovese F., Tauriello A., D’Auria M., Racioppi R., Viggiani L. 2014. Olive oil quality improvement using a natural sedimentation plant at industrial scale. Biosyst. Engine. 122:99-114.
Altieri G., Genovese F., Tauriello A., Di Renzo G.C. 2015. Innovative plant for the separation of high quality virgin olive oil (VOO) at industrial scale. J. Food Engine. 166:325-34.

Axelsson H., Madsen B. 2012. Centrifuges, sedimenting. Ullmann's Encyclopedia of Industrial Chemistry. John Wiley \& Sons, Ltd., Chichester, UK.

Baccioni L., Peri C. 2014. Centrifugal separation. In: C. Peri (Ed.), The extra-virgin olive oil handbook. John Wiley \& Sons, Ltd., Chichester, UK, pp. 139-154.

Beveridge T. Large-scale centrifugation. 2000. In: I.D. Wilson, E.R. Adlard, M. Cook, C.F. Poole (Eds.), Encyclopaedia of Separation Science. Academic Press, London, UK.

Carole C., Fedeli E., Jacini G. 1964. Gli impianti italiani per l'estrazione di olio da olive. Riv. Ital. Sost. Grasse 41:1-56.

Cimini A., Marconi O., Perretti G., Moresi M. 2014. Novel procedure for lager beer clarification and stabilization using sequential enzymatic, centrifugal, regenerable PVPP and crossflow microfiltration processing. Food Bioproc. Technol. 7:3156-65.

Civantos L. 1999. Obtención del aceite de oliva virgen. Editorial Agrícola Española S.A. Madrid, Spain, p. 316.

Costagli G. 2006. Differenziare le caratteristiche dell'olio extravergine di oliva: aspetti agronomici e tecnologici. Frutticultura 3:32-9.

Costagli G., Betti M. 2015. Avocado oil extraction processes: method for cold-pressed high-quality edible oil production versus traditional production. J. Agricult. Engine. 46:115-22.

Costagli G., Rapilly C., Franzoso M., Sjoberg M., Bonetti L., Ciman G.M., Lonardi F. 2016. Advances in post-fermented wine clarification by centrifugal technology. Wine Studies 5:7-13.

Di Giovacchino L. 1988. L'impiego del talco micronizzato nell'estrazione dell'olio dalle olive con il sistema continuo. Riv. Ital. Sost. Grasse 65:623-8.

Di Giovacchino L. 2010. Tecnologie di lavorazione delle olive in frantoio. Rese di estrazione e qualità dell'olio. Tecniche Nuove, Milano, Italy, pp. 278.

Di Giovacchino L., Costantini N., Ferrante M.L., Serraiocco A. 2002. Influencia del tiempo de batido de la pasta de aceitunas sobre los rendimientos en aceite y sobre la calidad química y organoléptica del aceite de oliva virgen obtenido con un decanter centrifugo con ahorro de agua. Grasas Aceites 53:179-86.

Di Giovacchino L., Solinas M., Miccoli M. 1994. Effect of extraction systems on the quality of virgin olive oil. J. Am. Oil Chem. Soc. 71:1189-94.

Frezzotti G. 1928. La centrifugazione dei liquidi oleosi. Risultati delle esperienze eseguite durante la campagna olearia 1926-27. Oleum VI.

García A., Brenes M., Martínez F., Alba J., García P., Garrido A. 2001. High-performance liquid chromatography evaluation of phenols in virgin olive oil during extraction at laboratory and industrial scale. J. Am. Oil Chem. Soc. 78:625-9.

Genovese F., Di Renzo G.C., Altieri G., Tauriello A. 2013. Mild separation system for olive oil: quality evaluation and pilot plant design. J. Agricult. Engine. 44:306-10.

Gila A., Beltrán G., Aymen Bejaoui M., Aguilera M.P., Jiménez A. 2017. How clarification systems can affect virgin olive oil composition and quality at industrial scale. Eur. J. Lipid Sci. Technol. [Epub ahead of print].

Gordillo B., Ciaccheri L., Mignani A., Gonzalez-Miret M., Heredia F. 2011. Influence of turbidity grade on color and appearance of virgin olive oil. J. Am. Oil Chem. Soc. 88:1317-27.

Guerrini L., Pantani L.O., Parenti A. 2016. The impact of vertical centrifugation on olive oil quality. J. Food Process Engine. 40:e12489. 
Gupta S.K. 1981. Scale-up procedures for disc-stack centrifuges. Chem. Engine. J. 22:43-9.

Harwood J., Aparicio R. 2000. Handbook of olive oil - analysis and properties. Aspen Publishers Inc., MD, USA, pp. 459-483.

Hermoso Fernandez M., Gonzalez Delgado J., Uceda Ojeda M., Garcia-Ortiz A., Morales Bernardino J., Frias Ruis L., Fernandez Garcia A. 1995. Elaboracion de aceite de oliva de calidad. II. Obtencion por el sistema de dos fases. Junta de Andalusia; Consejeria de Agricultra y Pescas. Apuntes 11/94.

International Olive Oil Council. 2015. Trade standard applying to olive oil and olive pomace oils. 2009, COI/T. 15/NC No3. Rev 8, February 2015.

Jiménez Marquez A., Hermoso Fernandez M., Uceda Ojeda M. 1995. Elaboracion del aceite de oliva virgen mediante sistema continuo en dos fases. Influencia de diferentes variables del proceso en algunos parametros relacionados. Grasas y Aceites 46:299-303.

Kiritsakis A.K. 1992. El aceite de oliva. A. Madrid Vincente Ediciones, Spain.

Lozano-Sanchez J., Cerretani L., Bendini A., Segura-Carretero A., Fernandez-Gutierrez A. 2010. Filtration process of extra virgin olive oil: effect on minor components, oxidative stability and sensorial and physicoch.emical characteristics. Trends Food Sci. Technol. 21:201-11.

Madsen N.F. 1989. Slender decanter centrifuge. Int. Chem. Engine. Symp. Ser. No. 113:281-99.

Martinez J.M., Gomez Herrera C., Janel del Valle C. 1957. Estudios fisico-quimicos sobre las pastas de aceitunas molidas. IV. Las gotas de aceite. Grasas y Aceites 8:112-20.

Martinez J.M., Gomez Herrera C., Janel del Valle C. 1959. Estudios fisico-quimicos sobre las pastas de aceitunas molidas. VII. Rotura de emulsiones aceite-alpechin. Grasas y Aceites 10:170-6.

Martinez J.M., Muñoz E., Alba J., Lanzon A. 1975. Informe sobre la utilización del analizador de rendimientos Abencor. Grasas y Aceites 26:379-85.

Masella P., Parenti A., Spugnoli P., Calamai L. 2009. Influence of vertical centrifugation on extra virgin olive oil quality. J. Am. Oil Chem. Soc. 86:1137-40.

Masella P., Parenti A., Spugnoli P., Calamai L. 2010. Nitrogen stripping to remove dissolved oxygen from extra virgin olive oil. Eur. J. Lipid Sci. Technol. 112:1389-92.

Masella P., Parenti A., Spugnoli P., Calamai L. 2012. Vertical cen- trifugation of virgin olive oil under inert gas. Eur. J. Lipid Sci. Technol. 114:1094-6.

Muñoz E., Alba J., Lanzon A. 1979. Informe de la Almazara Experimental del Instituto de la Grasa correspondiente a la campaña 1978-79. Grasas y Aceites 30:251-61.

Ottaviani M.F., Spallaci M., Cangiotti M., Bacchiocca M., Ninfali P. 2001. Electron paramagnetic resonance investigations of free radicals in extra virgin olive oils. J. Agricult. Food Chem. 49:3691-6.

Parenti A., Spugnoli P., Masella P., Calamai L. 2007. Influence of the extraction process on dissolved oxygen in olive oil. Eur. J. Lipid Sci. Technol. 109:1180-5.

Peri C. 2014. Filtration of extra-virgin olive oil. In: C. Peri (Ed.), The extra-virgin olive oil handbook John Wiley \& Sons, Ltd, Chichester, UK, pp 155-164.

Rodis P.S., Karathanos V.T., Mantzavinou A. 2002. Partitioning of olive oil antioxidants between oil and water phases. J. Agricult. Food Chem. 50:596-601.

Sacchi R., Savarese M., Del Regno A., Paduano A., Terminiello R., Ambrosino M. L. 2008. Shelf life of vegetable oils bottled in different scavenging polyethyleneterephthalate (PET) containers. Packaging Technol. Sci. 21:269-77.

Servili M., Taticchi A., Sordini B., Esposto S., Urbani S. 2012. Technological aspects of olive oil production. In: Olive Germoplasm - The Olive Cultivation, Table Olive and Olive Oil Industry in Italy. InTech. Chapter 8:151-172.

Sullivan F.E., Erikson R.A. 1961. Design - De Laval's "KQ value" spelled out. Design factors with the continuous disk centrifuge as a case point. Industr. Engine. Chem. 53:434-8.

Uceda M., Jiménez A., Beltrán G. 2006. Olive oil extraction and quality. Grasas y Aceites 57:25-31.

Valleggi M. 1966. Osservazioni preliminari sull'impianto $<<$ Centriolive $>>$ per la lavorazione continua delle olive. Industr. Agr. 4:9-12.

Veneziani G., Esposto S., Minnocci A., Taticchi A., Urbani S., Selvaggini R., Sordini B., Sebastiani L., Servili M. 2018. Compositional differences between veiled and filtered virgin olive oils during a simulated shel life. LWT - Food Sci. Technol. 94:87-95.

Vitagliano M., Radogna V.M. 1967. La centrifugazione nella oleificiazione delle olive. Confronto tra Centriolive e pressione. Industr. Agr. 5:461-80. 